\title{
Ecologization of Regional Industrial Complex in the Transition to Sustainable Development
}

\author{
Elena Dotsenko ${ }^{1, *}$, Natalia Ezdina ${ }^{1}$, and Svetlana Mudrova $^{1}$ \\ ${ }^{1}$ Russian University of Economics, Department of Political Economy and History of Economic \\ Science, 117997, Moscow, 36 Stremyanny lane, Russia
}

\begin{abstract}
Ensuring the sustainable development of a country or a single territory is a complex task, the main role in the implementation of which is the timely receipt of financial resources. This allows for the implementation of innovative economic and environmental policies aimed at diversification and ecologization of the regional economy, including a reduction in the negative impact on the environment, the introduction of new technologies at enterprises, the strengthening of environmental expertise and the consideration of the environmental factor in making managerial decisions, population and other activities. The regions became able to pursue an environmental policy only in the conditions of boosting the innovative activity in the leading industries. Together with the consolidation of environmental funds, this must be the main reason for efficient financing of environmental policy. So ecologization of industrial region economy means environmentalization of its economic development.
\end{abstract}

\section{Introduction}

Today there is a need for a significant change in financing for environmental protection. Among the main directions in this area are:

- "greening" the tax system, implying shifting the tax burden from the income of the population and the profit tax on increased taxes for businesses for consumption and reconsumption of natural resources (including electricity) and environmental pollution;

- accumulation of financial resources in the regions.

The priority of increasing the economic value allows solving at least two tasks in the transformation of the tax system:

- to make the price of products more adequate in relation to costs with assistance of differentiated taxes, including natural resources and damage to the environment;

- to promote compensation for environmental damage by the polluter, not by the society or by the "victims" of pollution (that is, to promote the implementation of the polluter pays principle).

The solution of these problems involves the establishment of increased taxes for environmentally hazardous products and activities and tax incentives for organic products and activities. Here, the state gives only the initial impetus, influencing with the help of taxes on prices, and everything else needs to be done by market mechanisms like influencing on

\footnotetext{
${ }^{*}$ Corresponding author: ktyf110372@,rambler.ru
} 
the behavior of producers and consumers, the demand and supply of products depending on the degree of its environmental friendliness.

In the restructuring of the tax system, two important aspects can be identified within the entire economy: increasing the proportion of "natural" taxes and creating tax incentives for the rational use and conservation of natural resources. It is necessary to change the proportions and increase the share of taxes in the environment-exploiting sector of the economy in the total amount of taxes. This will help to adequately reflect the role of huge natural potential in the Russian economy, more rational use of natural resources, and the removal of natural rent in favor of society.

Modern tax systems in the world and in Russia are concentrated primarily on levying taxes on the population, on profits, on added value, etc., that is, on labor and capital. While maintaining the total amount of taxes (fiscal neutrality), it is advisable to change the proportions in favor of increasing the share of taxes associated with the use of natural resources, and first of all, payments for the right to use natural resources, "Green" taxes, taxes on environmentally unfriendly activities, leading to environmental pollution. According to the available estimates, this share should significantly increase and make up a significant part of the state budget revenues.

\section{Materials and Methods}

The environmentalization of the tax system will facilitate the implementation of structural and technological policies, in particular the shift from the use of primary natural materials to secondary processed materials and wastes. Such a shift will not only reduce environmental degradation, but will also increase employment, since recycling and processing are more labor-intensive technologies than extraction of natural resources.

In general, it is necessary to create environmentally friendly systems of taxes, credits, subsidies, trade tariffs and duties in the economy [1-4].

It should be gradually shifted from the existing predominantly indirect taxation to direct natural-resource taxation. The latter has a number of benefits, because promotes:

- saving resources and preserving the natural environment;

- better tax collection;

- creation of effective funds for the protection and reproduction of natural resources;

- Increase the commercial efficiency of environmental activities for any owners, as resourcesaving is stimulated;

- creating the necessary prerequisites for improving the system of national accounts.

Direct natural-resource taxation should be carried out by taking into account in payments for traditional natural resources rental indicators, rather than quasi-rent (as is done now); registration in payments for pollution of the natural environment actually caused environmental damage.

A change in the tax system may include:

- consistent replacement of budget revenues of different levels from income tax, personal income tax, VAT, excises, etc. income from taxation of natural resources;

- implementation of measures for gradual adaptation of taxpayers to the new taxation conditions through the development of a tax credit and benefits for individual taxpayers;

- implementation of the taxation of land allotment and other types of real estate, taking into account the shift of the center of tax burden from buildings and structures to a land allotment within the real estate;

- formation of reserve funds in higher budgets to ensure support of lower-level budgets for the transition period to the new taxation system.

Tax reform should be implemented gradually so that taxpayers can adapt to the new taxation conditions. At the initial stage, the restructuring of taxation will be based on the 
principle of "fiscal neutrality" [5].

So far, the focus in the protection of the environment has been aimed only at rationalizing the nature protection measures themselves. Environmental protection activities, isolated from the issues of restructuring of the entire economy, are based on the assumption that a negative technogenic impact on the natural environment is given and the problem lies only in finding effective ways to reduce it. However, such an environmental concept is not enough, as it ignores more effective ways of preserving the environment through the targeted impact on the volume and nature of production, by incorporating the environmental aspect into the process of improving economic activity [6-8].

With this approach, the criteria and principles for restructuring economic activities must meet the goals of preserving the natural environment. To do this, it is necessary to determine the quantitative characteristics of the impact on its condition: the characteristics of industrial waste (including emissions), the environmental costs for their disposal and disposal, the residual pollution emissions into the environment, the economic damage from these emissions [9-10].

The economic feasibility of each type of economic activity should be determined taking into account the environmental costs associated with it and the damage from environmental pollution.

Sustainable development of the region depends on the real ecological and economic balance of its economic activities. The pace of its ecologization should correspond to the rates of social and economic development of the region or outstrip them in order to prevent a critical reduction of the ecological capacity of the territory, its natural and resource potential and not create a crisis ecological situation. For sustainable social and economic development of the territory, the resource intensity and energy intensity of the gross regional product, the state of the environment, mean no less than, for example, a favorable economic and investment climate

Competitive advantages in small business can be achieved both through innovation and orientation to the provision of services that are in demand. The decisive factor in both cases is that due to the proximity and spatial limitations of the market, small and medium-sized enterprises can more quickly and accurately recognize the needs of customers. The flexible structure of products and services allows quick making individual or innovative decisions by offering new products or services to the market in a short time. This circumstance determines the urgency of the ecologization of economic activity for small and medium-sized businesses.

In terms of greening economic activity, large enterprises have several advantages over small and medium-sized businesses. The most important of these is the use of the law of economies of scale. With an increase in the scale of production, it becomes possible to use resource-saving economical technologies, to reduce losses of material resources from $50 \%$ (in single and small-scale production) to $5 \%$ (in mass production). With more opportunities, large business is more motivated in the field of greening its operations.

Additional opportunities for greening are seen in the integration of small, medium and large businesses in the region. If the costs of transition to greening the economic activities of an enterprise can be reduced through merger with other firms, joint cost sharing, horizontal integration, the search for common technical solutions, joint for firms and industries, it is most likely that the enterprise will decide on such a transition voluntarily for improve their business and will not wait for any government support. Consequently, enterprises that have switched to such a sectoral approach through cooperation will achieve certain advantages with ever increasing competition in the world market. Intra-sectoral integration will allow enterprises not only to solve the problems arising before the primary producer of products, but also problems related to raw materials, sales and consumers. The need for such integration can be justified by the fact that any innovative processes most often arise not within the company itself, but between companies 
From the point of view of strategic regional planning, the sectoral approach offers the following advantages:

- regulation by different authorities is more effective if it is focused on the real industrial sector;

- self-management and development of own environmental policies and procedures (monitoring, insurance, controlling, etc.) more efficiently within the sector;

- supplementing informal interaction between enterprises forming this industrial sector;

- positive public opinion is most significant if it extends to the whole sector of the economy.

In accordance with the rule of the integral resource, the industries competing in the sphere of the use of specific natural systems inevitably damage each other the more strongly, the more significantly they change the jointly exploited ecological component. In accordance with this rule, the creation of regional technological systems of low-waste and non-waste production on the principles of partnership will significantly reduce the damage caused to each other. However, for technical and economic reasons, the transition to wasteless technology can not be carried out immediately. The real way of ecologicalization of economic activity in the field of technology is a gradual transition to low-waste, and then to wasteless, closed cycles.

\section{Results and Discussion}

Sustainability implies the achievement of a reasonable balance between socio-economic development and preservation of the environment, the extension of the environmental management system (EMS) at the enterprises of the region contributes to reducing the burden on the environment and, as a result, improving the ecological and economic balance of regional development, which will positively affect the investment attractiveness the region, including by reducing environmental risk.

On the part of regional authorities, management and stimulation of the process of greening economic activities must be carried out primarily through the support of enterprises introducing environmentally friendly technologies and developing a policy of greening. The instruments of this support may include: targeted tax benefits, including deferral of tax collection; the reduction of the profit tax by the amount that enterprises plan to invest in the greening of their production; reduction of value added tax when purchasing new technological equipment by the enterprise that meets modern environmental requirements; exemption from payment of taxes for certain categories of taxpayers; withdrawal of individual elements of taxation objects from the taxable base. Another stimulating measure of using the company's own resources for the greening of production is the introduction of the practice of accelerated depreciation of fixed assets of ecological purpose and environmentally friendly equipment.

Today the basic principles of energy saving are defined:

- firstly, not so much a rigid economy of all types of energy as its rational use, including the search for and development of new non-traditional sources of energy conservation

- secondly, the widespread use of both domestic and industrial meters for regulating the consumption of electricity and heat;

- thirdly, the introduction of new technologies that reduce the energy intensity of production.

The introduction of eco-innovations should become a factor of business activity, and for this the regional authorities should include environmental entrepreneurship in the system of regional development priorities. Since the quality of life of the working population is determined primarily by its real incomes, increasing the competitiveness of enterprises in the region can contribute to the growth of wages in the business sphere and increase the level of social protection of the disabled population by increasing the revenue side of the budget and, as a result, programs. 
The second direction of influence on social development is associated with the reduction of harmful effects on public health as an important component of the quality of life.

To address the issue of supplying the population with clean drinking water, the following activities can be carried out:

- revaluation, assessment or exploration of groundwater resources on subsoil sites operated by municipal institutions;

- clearing the channels of small rivers and strengthening the banks of rivers used for water abstraction in order to improve their watercourse;

- reducing the anthropogenic pressure on large water bodies and monitoring the level of contamination of these reservoirs in order to identify the sources of pollution, eliminate the detected violations and impose fines on the perpetrators;

- revision of pressure hydraulic structures for the determination of their owners and establishment of compliance of these facilities with the norms of technical safety;

- organization of supply of the population with high quality imported drinking water in those territories where there are no own reserves of fresh water.

Ecological and economic regulation of market relations will undoubtedly help to improve the ecological situation in the region, which has two goals:

- restriction of inefficient competition with a view to removing non-environmentally friendly products, technologies and equipment from the competitive environment;

- development of market mechanisms proper (environmental insurance and trading of various kinds of quotas in the use of natural resources).

The environmentalization of economic development will be more successful in stimulating enterprises to form an active environmental policy, which is understood as a "double win" policy, which allows reducing the negative impact on the environment and the resource component in production costs.

The regional policy of ecologization should be aimed at achieving the main goals of social and economic development: ensuring the environmental safety of the population as a component of the quality of life and enhancing the competitiveness of the regional economy. These goals are interrelated, and therefore ensuring the required level of environmental purity of production and product should become a strategic goal of economic entities and regional policy.

Along with the ecologization of the branches of the economy that directly exploit natural resources, an array of such economic options that are based on the development of industries and activities not directly related to the exploitation of natural resources is of interest. In this vein, first of all, it is worth noting the potential for an environmental improvement of the situation through structural adjustment of the economy. To implement it, it is necessary to develop an effective structural policy, with special attention given to the creation of legal and organizational conditions for ecological restructuring of the economy in accordance with the requirements of rational use of all types of resources, preservation and improvement of the environment, and environmental safety of production and products.

\section{Conclusion}

The essence of the environmentally oriented change in the structure of the economy consists in stabilizing the growth and production of nature-exploiting and resource-extracting industries with the rapid development on a modern technological basis of all industries in the product-based integration associated with the transformation of natural resources and the production of the final product on its basis. We are talking about the global redistribution of labor, material, financial resources in the national economy in favor of resource-saving, technologically advanced industries and activities. 


\section{References}

1. A.A. Khoreshok, S.A. Zhironkin, M.A. Tyulenev, G.A. Barysheva, V.Y. Blumenstein, M.C. Hellmer, S.V. Potyagailov, IOP Conf. Ser.: Mater. Sci. Eng., 142: 1, 012122 (2016)

2. E. Shavina, O. Kalenov, E3S Web of Conferences 21, 04025 (2017)

3. F. Agafonov, A. Genin, O. Kalinina, O. Brel, O. Zhironkina, E3S Web of Conf., 15, 04011 (2017)

4. E.A. Gasanov, M.A. Gasanov, Economics and Innovation Management, 1, 30-38 (2017) DOI: $10.26730 / 2587-5574-2017-1-30-38$

5. N.N. Golofastova, V.G. Mikhailov, I.V., Seredyuk I.V. Economics and Innovation Management, 1, 66-75 (2017) DOI: 10.26730/2587-5574-2017-1-66-75

6. A. Balabanova, V. Balabanov, E. Dotsenko, N. Ezdina, E3S Web of Conf., 15, 04013 (2017)

7. S.A. Zhironkin, K.A. Kolotov, O.V. Zhironkina, Economics and Innovation Management, 1, 4-16 (2017) DOI: 10.26730/2587-5574-2017-1-4-16

8. O. Borisova, V. Frolova, E. Merzlikina, E3S Web of Conf., 21, 04016 (2017)

9. V. Osipov, T. Skryl, N. Nevskaya, E. Shavina, International Business Management, 10:9, 1649-1657 (2016)

10. V. Frolova, O. Dolina, T. Shpil'kina, E3S Web of Conf., 21, 04018 (2017) 